\title{
High Rigidity and Vibration Endurance Bar for Deep Holes
}

\author{
Evgenia Evgenieva \\ Departament of Engineering technologies \\ and technosphere safety \\ Pskov State University \\ Pskov, Russia \\ Zhen_sheny@mail.ru \\ Pavel Maltsev \\ Departament of Engineering technologies \\ and technosphere safety \\ Pskov State University \\ Pskov, Russia \\ Inertan@gmail.com
}

\begin{abstract}
Different constructions of bars are analyzed in the article, all of which are based on the idea of creating prestressed state in material. Improved construction of bar is proposed for equable spreading of elasticity zone along axis of boring bar.
\end{abstract}

Keywords - Grinding, boring, rigidity, vibration endurance, stress, Hooke's law, dissipation.

\section{INTRODUCTION}

One of the problems which appear during boring and internal grinding of deep holes is a complexity of providing a required rigidity and vibration endurance of bar in the limited space. The problems appear during machining in conditions of reduced rigidity of manufacturing system. There are two basic ways to solve them: to increase rigidity and decline value of cutting force.

One of the best solutions of increasing rigidity and vibration endurance is making prestressed state in the bar material. The point of this method is mechanical influence on the bar material. As a result, crystal lattice of material is deformed and the distance between atoms decreases. This impaction takes place according to Hooke's law and doesn't lead to plastic deformation. In the same time, rigidity of bar goes up, vibration endurance and energy dissipation are improving and the logarithmic decrement of oscillations is increasing.

\author{
Igor Nikiforov \\ Departament of Engineering technologies \\ and technosphere safety \\ Pskov State University \\ Pskov, Russia \\ Nikiforov.i.p@mail.ru \\ Sergei Dmitriev \\ Departament of Engineering technologies \\ and technosphere safety \\ Pskov State University \\ Pskov, Russia \\ Dmitrievsi55@gmail.com
}

\section{MATERIALS AND METHODS}

There are many researchers about ways to increase rigidity and vibration endurance of bars by creating prestressed state their body [1-6].

One of the accomplished solutions is a boring bar for stepped deep holes in hardly processed parts, welded of different materials [1]. The bar has an expanding taper which is set in an empty body from the cutting insert side. The taper is connected with thread kernel which has a regulating nut with a thrust on the end of the body. The expanding taper is made of steel with a hardness $<200 \mathrm{HB}$ and empty body is made of steel with a hardness 350-370 HB. The bar is mounted in a turret CNC machine through a split bushing.

This construction provides even spread of stretched tension in a cross section body of the bar. Radial component of cutting force leads to bar bending, and in according to machining scheme, its direction is essentially permanent. It means that bending can be compensated more effectively.

Other known construction is low-vibration tool holder [2] (Fig. 1) with a tool holder base body 1 and a tensioning arrangement 2 which provides axial tensioning of the tool holder base body and which is simultaneously tensioned in a radially flexible way with respect to the tool holder base body. 


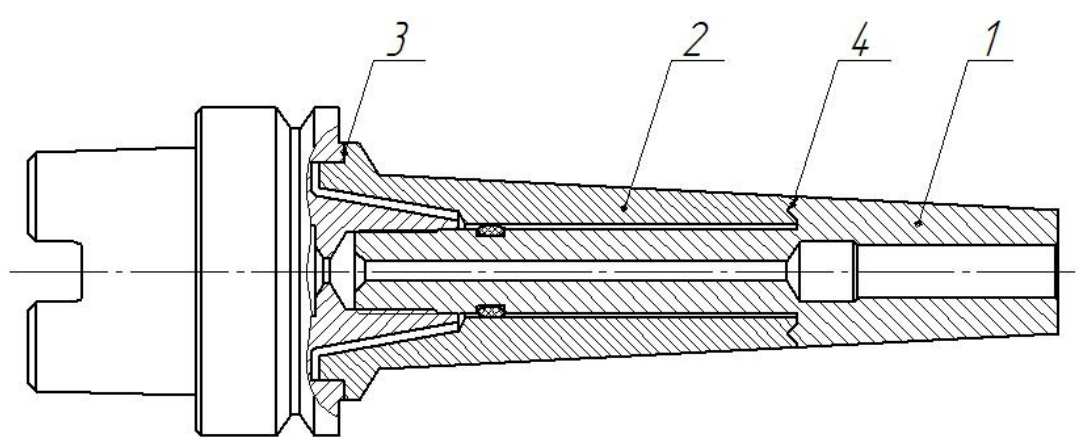

Fig. 1. Tool holder by RU 2400330.

This tool holder is less susceptible to vibration than previously known tool holders, which ensures better true running even during operation and in particular when heatinduced expansion of materials occurs, since the clamping arrangement which is integrated in the tool holder is continuously centered with respect to the tool holder base body. Furthermore, such a tool holder, in particular within a modular design, can be adapted very flexibly to different types of tools and workpiece machining processes. This holder has one or several formed seats 3 and 4 which interact during movable contact with one or several mating surfaces.

The most part of tensions made by such bar has axial direction and its construction is good for tools with constantly change directions of radial component of cutting force. Besides, location of formed seats and mating surfaces on the outer side of the bar leads to increased requirement of careful during using and storage.

Another construction of boring bar [3] consist of body 1 which face surface has a hole with sliders 2 to tune the damper, O-rings 3 and the absorber 4 , relocatable by a diagonal tuner 5 (Fig. 2). The bar also has end plug 6 and cartridge 7 to mount the cutting insert. This construction provides protection of absorber 4 and O-rings 3 , however, not good for rotatable bar because of imbalance which emerges in the presents of tuner 5 and its variable position. Besides rigidity increases on the limited length of the bar.

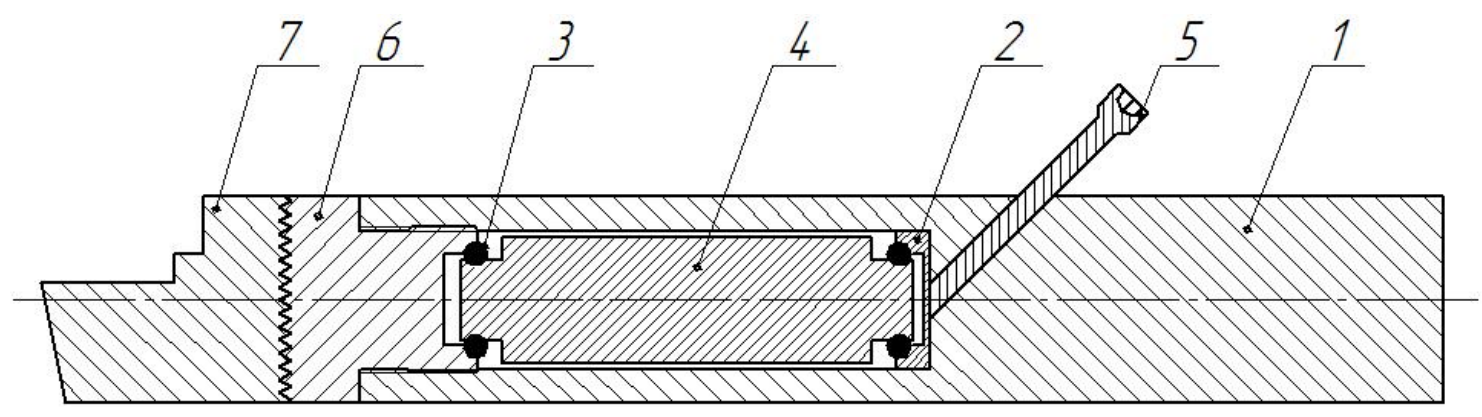

Fig. 2. Damper boring bar with inner absorber and tuner.

The enhanced version of previous construction is a boring bar with improved stiffness [4]. A tunable or tuned boring bar having increased stiffness is provided. Increasing the stiffness of the bar increases the natural frequency, thereby reducing directional deformation of the bar during use. The tunable boring bar includes a distal portion configured to support a tool, a proximal portion configured for attachment to a support structure of a metalworking machine, and a body, which is at least partially tubular, extending between the proximal portion and the distal portion. The tubular portion of the body has an elongated cylindrical cavity. The body of the boring bar includes a core layer 1 formed from a first material and a coating layer 2 formed from a second material (Fig. 3). The second material has a higher modulus of elasticity than the first material. In certain configurations, the coating layer is bonded to the core layer by cladding, welding, chemical adhesives, chemical vapor deposition, pulsated plasma diffusion, or combinations thereof.
This design provides an increase bar rigidity over the entire length of the body, a decrease imbalance due to a decrease length of the screw, but does not protect the outer layer of the coating from external factors.

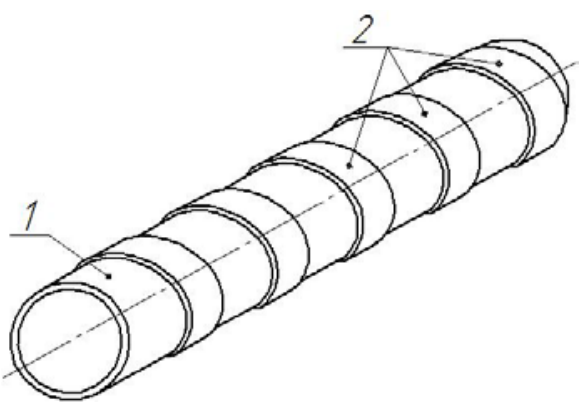

Fig. 3. Boring bar with improved stiffness by US 10040127. 


\section{RESULTS AND DISCUSSION}

A new bar with high rigidity and vibration endurance is developing now. It will provide an opportunity to solve mentioned problems of increasing spreading tension along the body length and decreasing interaction external influence on elements which are responsible for creating prestressed state in boring bars, tool bars, etc.

The base of the offered solution is another widely known tool for hardening processing inner cylindrical surfaces [5]. It is made in a shape of cylindrical shells 1 and 2 , one of them has a collar at the end and another one has a flange (Fig. 4).

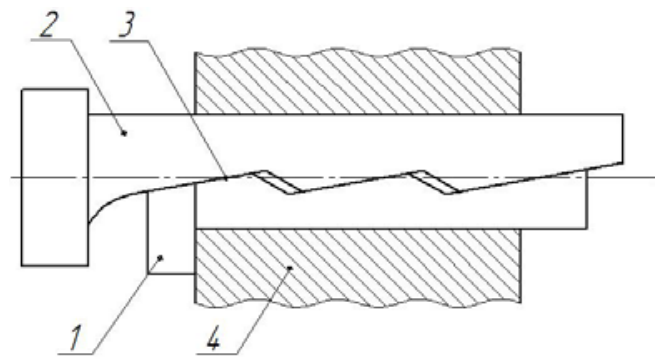

Fig. 4. Tool for hardening processing inner cylindrical surfaces by SU 854696.

Those shells have stepped bevels 3 forming wedge pairs. The angle of bevels to longitudinal axes of the shell and bar is bigger than the self-holding angle on 1-2 degrees. Bevels length and angle of their surface on the each step are equal. The amount and value of the steppes are defined by length of the hole, its diameter and condition of the bevels angle excess above the self-holding angle.

Radial force emerges during the axial moving those shells in the hole 4 and interacts on the walls of the hole. Accordingly, a new prestressed device could be got by placing such shells into the hole of the body.

This solution (Fig. 5) is based on construction tool bar using which has an empty body 1 with cylindrical hole which includes a system 2 for creating prestressed state in the bar. This system consists of movable 3 and unmovable 4 shells and a nut 5 . Stepped bevels 6 are made on the both shells for forming wedge pairs. Unmovable shell 4 is fixed on the body and movable shell 3 has a thread journal 7 with a nut 5 . The journal 7 partially located outside the body 1 . The opposite end of the movable shell 3 has the mating surfaces and thread holes for tool 8 fixation. Plenty of bevels 6 will increase life time of the bar and provide equable spreading tensions along its length, while the body 1 will provide shells protection from external influence.

Partial location of thread journal 7 provides free nut 5 moving during creating prestressed state. To increase bar rigidity one end of the movable shell 3 can be provided by a collar 9 and between it and body end is located length compensator 10 such as set of rings. It will allow to get rid of axial tensions in the tool 8.

In the preferable construction value of the bevels angle to the body axis was not less than the angle of friction, which for steel shells is not less than $1^{\circ} 25^{\prime} 56^{\prime \prime}$ similarly metric taper. The maximum value for this angle is about $10^{\circ}$ which fits for composite or polymer materials of shells.

The developing high rigidity and vibration endurance bar for deep holes has an empty (for instance, cylindrical or conical) body with cylindrical hole, which provides simplicity and high accuracy of machining. Unmovable shell of the system for creating prestressed state is fixed by radial screws which are located in the body walls. In the preferable construction the screws amount is equal the amount of bevels.

Shells are made of the same material (for instance, constructed or alloy steel) which is softer than material of the body, for example, due to different heat treatment or composition. The thread journal with a nut can include a device or material for providing self-locking antidisassembly such as locknut, spring lock washer, etc.

Shells are made of a one blank for machining error decreasing. It can be provided by electrical-discharging cutting with subsequent finishing bevels for decreasing of resistance forces sliding. For the mentioned result lubricant or grease also can be inflicted on the out surface of movable shell and bevels.

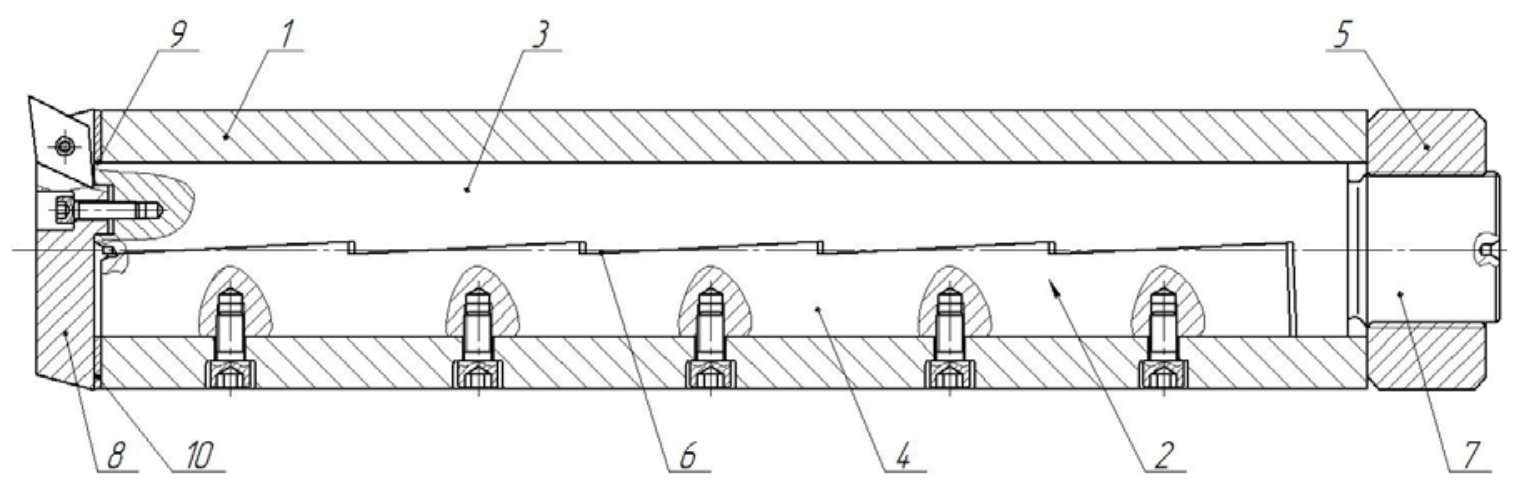

Fig. 5. Developing high rigidity and vibration endurance bar for deep holes. 
The mounting shells surface can be located perpendicularly to direction of radial component of cutting force during using bar for the boring tool. It will have a positive influence due to compress tensions emerging in shells and sections A and B of the body wall (in according to Fig. 6) will partially compensate this component. At the same time, sections $\mathrm{C}$ and $\mathrm{D}$ of the body wall will have the respond stretching tensions and will not increase a moment, which is created by a tangential component of cutting force.

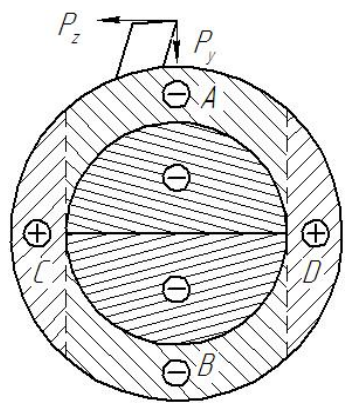

Fig. 6. Cross-section of the developing bar.

\section{CONCLUSIONS}

The developing bar can be used in the serial production for edge and grinding of deep holes with different diameters.

\section{REFERENCES}

[1] V.V. Maksarov, D.F.Osminko and T.S.Golikov, "Bar for boring stepped deep holes in difficult-to-cut dissimilar welded workpieces," RU Patent 191536, August 12, 2019.

[2] F. Haimer, "Tool holder characterised by low vibration," RU Patent 2400330, October 20, 2009.

[3] A. Yadav, D. Talaviya, A. Bansal, and M. Law, "Design of ChatterResistant Damped Boring Bars Using a Receptance Coupling Approach," Journal of Manufacturing and Materials Processing, vol. 4, no. 2, p. 53, Jun. 2020 [Online]. Available: http://doi.org/10.3390/jmmp4020053.

[4] Ruy Frota de Souza Filho, "Boring bar with improved stiffness" US Patent 10040127, Mar 14, 2014.

[5] S.P. Krapivin, A.O. Reidman and E.T. Vasilevskyi, "Tool for hardening processing of internal cylindrical surfaces," SU Patent 854696, November 15, 1979.

[6] E. I. Yatsun, O.S. Zubkova, I.S. Karnaukhov, A. Gorchakov, "Antivibration tool holder," Modern materials, equipment and technologies, vol. 23, pp. 80-90, 2019. 